*DR. ZULFAQAR A. KHAN

Saudi Arabia.

DR. ADEL M. ASSIRI

Saudi Arabia.
Article received on:

$29 / 09 / 2007$

Accepted for publication: 18/10/2007

\title{
*Correspondence Address:
}

Dr. Zulfaqar A. Khan (zkhan7@gmail.com.)

Saudi German Academy \& Research Centre, P.O.Box: 2550

Jeddah 21461, Saudi Arabia

\begin{abstract}
Objectives: To assess the associations of obesity and hypertension in diabetics and non-diabetics. Patients and Methods: A total of 430 Saudi patients suffering from non-insulin-dependent (type 2) diabetes mellitus comprising of 205(48 \%) males and 225(52 \%) females were studied. Height and weight were measured for calculating body mass index (BMI). The type 2 diabetics and non-diabetic individuals were investigated separately to determine the prevalence of obesity and overweight. Systolic and diastolic blood pressure was recorded using the standard method in a sitting position. The patients were diagnosed as diabetics and hypertensive on the criteria of the World Health Organization. Results: The prevalence of obesity was $16.7 \%$ and $22.9 \%$, and overweight was $27.1 \%$ and $22.9 \%$ in the total men and women studied in healthy non-diabetics; while the prevalence of obesity was $26.8 \%$ and $42.7 \%$, and overweight was 45.8 and $38.2 \%$ in the total men and women, in the diabetics respectively. In diabetic subjects, glycemic status $\left(\mathrm{HbA}_{1 \mathrm{c}}\right)$ and BMI had coefficient of correlation between 26 matched pairs as $r=0.36$, but not impressive. In over-all population, irrespective of gender, the diabetic subjects had higher obesity/overweight (ob/ow) ratio value $(0.84)$ than non-diabetics $(0.79)$. The prevalence of $\mathrm{HT}$ in non-diabetic group was $4.42 \%$ in males compared to $2.1 \%$ in females, while in the diabetic group the prevalence of HT was $24.39 \%$ in males and $41.33 \%$ in females, respectively. Prevalence of HT in diabetics was higher in females than males, in contrast to non-diabetics. Conclusion: Our study shows that obesity and hypertension are both contributing factors in the development of type 2 diabetes mellitus; and the measures should be adopted for control of obesity and hypertension to reduce the cause of diabetes mellitus.
\end{abstract}

Key words: Glycosylated hemoglobin, hypertension, obesity, type 2 diabetes mellitus.

\section{INTRODUCTION}

Overweight is defined as relative weight up to $20 \%$ above normal, and obesity relative weight over $20 \%$ above ideal body weight ${ }^{1,2}$. Obesity often precedes the development of non-insulin dependent diabetes mellitus (NIDDM) which accounts for 80 to $90 \%$ of the diabetes, and that the obese patients are usually hyperinsulinemic ${ }^{3}$. Obesity is implicated for several important diseases, especially hypertension, coronary heart diseases, dyslipidemia, diabetes mellitus, breast cancer, and osteoarthritis ${ }^{4-7}$. Like-wise, the important risk factors for type 2 diabetes mellitus include obesity, 
ethnicity, age, sex, sedentary lifestyle, family history, and perinatal influences ${ }^{8}$. Obesity is a major epidemic in United States ${ }^{9}$ and in a trial for hypertension, weight loss produced slightly greater reductions in blood pressure than did sodium restriction ${ }^{10}$.

Diabetes mellitus (DM) and hypertension (HT) are both multi-factorial disorders which occur at a higher prevalence in elderly and result from both genetic and environmental etiological factor ${ }^{11,12}$ and occur frequently in obese individuals. Like DM, HT is also one of the most common causes of morbidity and mortality in humans ${ }^{13}$. Several studies have shown that a close association between HT and DM exists even in different ethnic groups where the prevalence of $\mathrm{HT}$ is significantly higher in the patients with non-insulin dependent diabetes mellitus $^{14-16}$. It has been reported that the link between diabetes and essential HT is hyperinsulinemia ${ }^{17,18}$. Diabetes mellitus and $\mathrm{HT}$ are interrelated diseases that strongly predispose people to atherosclerotic cardiovascular disease, and hence have been referred to as "the bad companions"16.

Though association between development of non-insulin dependent diabetes mellitus and obesity has been shown, yet several aspects of this association are not yet clear $^{19}$. Significant ethnic differences have been reported in the nature and also the complications and prevalence of $\mathrm{HT}$, and obesity in patients with $\mathrm{NIDDM}^{18,20,21}$. In a continued study on the diabetic patients of unique ethnic community of Makkah, Saudi Arabia, where-in the dyslipidemic pattern and lipid peroxides level were determined $^{22}$, the associations of obesity and hypertension in diabetics and non-diabetics are evaluated, here.

\section{MATERIALS AND METHODS}

A total of 430 Saudi patients of Makkah area suffering from non-insulin-dependent (type 2) diabetes mellitus comprising of $205(48 \%$ ) males and $225(52 \%)$ females were the subjects of our study. The patients were diagnosed as diabetics on the basis of WHO criteria $^{23,24}$; fasting whole blood venous $>6.7 \mathrm{mM}(120 \mathrm{mg} / \mathrm{dl})$ and / or the value 2 hours after the glucose load $>10.0 \mathrm{mM}$ $(180 \mathrm{mg} / \mathrm{dl})$. Subjects with an age of onset $>30$ year and dependent on dietary control or use of oral hypoglycemic drugs were classified as type 2 diabetics and included in our study. 96 normoglycemic subjects of whom $48(50 \%)$ were males and 48(50\%) females without having any classical diabetic symptoms and signs, from the same population, served as control.

The fasting blood sample from the patients and control were collected by venipuncture in heparinized tubes (or $\mathrm{K}$ oxalate/Na fluoride), and / or in standard plain tubes for sera. Glycosylated hemoglobin $\left(\mathrm{HbA}_{1 \mathrm{c}}\right)$, which is a reliable index and invaluable tool of average glycemic control $^{25}$, was determined using BM/Hitachi system, based on the turbidometric immunological inhibition assay for hemolyzed whole blood (Kit No. 1822039). Triglycerides (TG), total cholesterol, high density lipoprotein cholesterol (HDL-C), low density lipoprotein cholesterol (LDL-C) were determined as described earlier $^{22}$. Lipid peroxides level was determined by the reaction with thiobarbituric acid ${ }^{26}$.

Height and weight were measured by using standard techniques according to WHO report ${ }^{27}$. The body mass index (BMI) is well correlated with measures of body fat and is defined as weight $(\mathrm{kg})$ divided by height ${ }^{2}\left(\mathrm{~m}^{2}\right)$. Using this index, BMI was calculated ${ }^{28}$. The type 2 diabetics and non-diabetic individuals were investigated separately to determine the prevalence of obesity and overweight. A BMI value of 18.5-24.9 was considered normal-weight persons as reference group, while a BMI value between 25.0 - 29.9 overweight, and 30 and over was considered obese ${ }^{29}$.

Systolic and diastolic blood pressure was recorded using the standard method in a sitting position. Diagnosis of 
HT was based on WHO criteria ${ }^{30}$. Values of systolic pressure $\geq 140 \mathrm{~mm} \mathrm{Hg}$ and/or diastolic pressure $\geq 90$ $\mathrm{mm} \mathrm{Hg}$ and individuals on antihypertensive drugs were considered as hypertensive ${ }^{31}$.

The data was analyzed by z-statistic, student's t-test and chi square test where appropriate. Relationship between two variables was determined by Pearson's Product
Moment Correlation Coefficient (r).

\section{RESULTS}

Physical characteristics, BMI value and the levels of glycated hemoglobin for each individual in diabetic (430) and non-diabetic (96) subjects are presented in Table I.

Table-I. Certain characteristics of study population (Mean \pm SEM).

\begin{tabular}{|c|c|c|c|c|}
\hline & \multicolumn{2}{|c|}{ DM type 2 patients } & \multicolumn{2}{|c|}{ Control group } \\
\hline & Male & Female & Male & Female \\
\hline Age (yr) & $49.5 \pm 1.13$ & $48.5 \pm 1.11$ & $48.5 \pm 0.86$ & $46.5 \pm 0.92$ \\
\hline Height (m) & $163.05 \pm 1.08$ & $154.9 \pm 1.04$ & $165.3 \pm 0.73$ & $155.8 \pm 0.58$ \\
\hline Weight (kg) & $74.32 \pm 1.49$ & $73.26 \pm 1.73$ & $66.5 \pm 0.89$ & $62.5 \pm 0.92$ \\
\hline $\begin{array}{l}\text { Body mass index } \\
\left(\mathrm{kg} / \mathrm{m}^{2}\right)\end{array}$ & $27.84 \pm 0.70$ & $29.63 \pm 0.80$ & $26.88 \pm 0.36$ & $28.58 \pm 0.50$ \\
\hline $\mathrm{HbA}_{\mathrm{Ic}}(\%)$ & $11.47 \pm 0.23^{*}$ & $10.71 \pm 0.20^{*}$ & $6.06 \pm 0.17$ & $5.65 \pm 0.14$ \\
\hline
\end{tabular}

The results of blood glucose levels were published elsewhere ${ }^{22}$. The prevalence and association of obesity and overweight in the total diabetic and non-diabetic population and segregated as men and women are shown in Table II.

The prevalence of obesity was $16.7 \%$ and $22.9 \%$, and overweight was $27.1 \%$ and $22.9 \%$ in the total men and women studied in healthy non-diabetics; while the prevalence of obesity was $26.8 \%$ and $42.7 \%$, and overweight was 45.8 and $38.2 \%$ in the total men and women, in the diabetics respectively. Prevalence of obesity was higher significantly (42.7\%) among diabetic women compared to $22.9 \%$ among non-diabetic women $(p<0.001)$.
The prevalence of obesity was lower while overweight was higher among men compared to the women in diabetic group; a pattern similar to non-diabetics but aggravated significantly. On the other hand, overweight men were more prevalent $(45.8 \%)$ than the women $(38.2 \%)$ in the diabetic group and also in the non-diabetic group, $27.1 \%$ compared to $22.9 \%$, respectively. If obese and overweight populations are grouped together, then almost $3 / 4^{\text {th }}$ of the diabetic individuals were either obese or overweight. Both in men and women, the prevalence of obesity and overweight are significantly higher in the diabetic individuals compared to the non-diabetic individuals $(p<0.001)$. In diabetic subjects, glycemic status $\left(\mathrm{HbA}_{1 \mathrm{c}}\right)$ and $\mathrm{BMI}$ had coefficient of correlation between 26 matched pairs as $r=0.36$, which was not impressive. 


\begin{tabular}{|c|c|c|c|c|c|c|}
\hline \multirow[t]{2}{*}{ Population } & \multicolumn{3}{|c|}{ Diabetic } & \multicolumn{3}{|c|}{ Non-diabetic } \\
\hline & $\begin{array}{c}\text { No. } \\
\text { investigated }\end{array}$ & $\begin{array}{c}\text { Overweight } \\
\text { No. }(\%)\end{array}$ & $\begin{array}{l}\text { Obese } \\
\text { No. (\%) }\end{array}$ & $\begin{array}{c}\text { No. } \\
\text { investigated }\end{array}$ & $\begin{array}{c}\text { Overweight } \\
\text { No. (\%) }\end{array}$ & $\begin{array}{l}\text { Obese } \\
\text { No. (\%) }\end{array}$ \\
\hline Male ${ }^{\text {(a) }}$ & 205 & $94(45.85)$ & $55(26.83)$ & 48 & $13(27.08)$ & $8(16.67)$ \\
\hline Female $^{(b)}$ & 225 & $86(38.22)$ & $96(42.67)$ & 48 & $11(22.92)$ & $11(22.92)$ \\
\hline Total ${ }^{(c)}$ & 430 & $180(41.86)$ & $151(35.12)$ & 96 & $24(25.0)$ & 19 (19.79) \\
\hline \multicolumn{7}{|c|}{$\begin{array}{l}\text { Statistical significant of the difference in the results of obesity in diabetic and non-diabetic population } \\
\qquad \begin{array}{l}\text { (a) } x^{2}=14.79 ; \quad D F=2 ; \quad p<0.001 \\
\text { (b) } x^{2}=26.88 ; \quad D F=2 ; \quad p<0.001 \\
\text { (c) } x^{2}=39.61 ; \quad D F=2 ; \quad p<0.001\end{array}\end{array}$} \\
\hline
\end{tabular}

Prevalence of HT in the total number of type 2 DM and Table III. non-diabetic males and females screened are shown in

\begin{tabular}{|c|c|c|c|c|c|c|c|}
\hline \multicolumn{4}{|c|}{ Diabetic } & \multicolumn{4}{|c|}{ Non-diabetic } \\
\hline Population & $\begin{array}{c}\text { No. } \\
\text { Investigated }\end{array}$ & Total No. HT & $\begin{array}{c}\text { Prevalence } \\
\text { of HT }(\%)\end{array}$ & $\begin{array}{c}\text { Total No. } \\
\text { Investigated }\end{array}$ & $\begin{array}{c}\text { Prevalence } \\
\text { of HT }(\%)\end{array}$ & $\mathrm{X}_{2}^{*}$ & $p$-value \\
\hline Male & 205 & 50 & $(24.39)$ & 48 & $2(4.2)$ & 8.5 & $<0.005$ \\
\hline Female & 225 & 93 & $(41.33)$ & 48 & $1(2.1)$ & 25.3 & $<0.001$ \\
\hline Total & 430 & 143 & $(3.33)$ & 96 & $3(3.13)$ & 34.0 & $<0.001$ \\
\hline
\end{tabular}

The prevalence HT in non-diabetic group was $4.42 \%$ in males compared to $2.1 \%$ in females, while in the diabetic group the prevalence of HT was $24.39 \%$ in males and $41.33 \%$ in females, respectively. Similar to obesity, the prevalence of HT is highest in diabetic females. The difference in the prevalence of HT in the two groups was statistically significant in both males $(p<0.05)$ and females $(p<0.001)$. The increase in prevalence of $\mathrm{HT}$ in diabetic was significantly higher in the females compared to males. Among the non-diabetics, males showed a higher prevalence of HT as compared to the females.
Over all, the prevalence of HT was significantly higher in the diabetic group compared to the non-diabetic group $(p<0.001)$.

\section{DISCUSSION}

The high prevalence of obesity and overweight in the diabetic individuals points to the fact that obesity is one of the major etiological factors in the development of diabetes. The role of obesity in the etiology of diabetes mellitus is well documented and according to World Health Organization "Expert Committee on diabetes 
mellitus", obesity is considered as the most powerful known risk factor for the development of type $2 \mathrm{DM}^{32}$. It was reported that persons having genetic susceptibility, the presence of obesity may act more as a potentiator of type $2 \mathrm{DM}^{33}$. It has been suggested that obesity and the other risk factors associated with life style modernization may interact and result in increased prevalence of type $2 \mathrm{DM}^{34}$.

Obesity always causes some degree of insulin resistance, a poorly understood phenomenon, where-in the number or affinity of insulin receptors is reduced in some patients; other have normal insulin binding but abnormal post-receptor responses and hence predisposition to hyperglycemia. The high obesity/overweight (ob/ow) ratio value is indicative of a relatively higher prevalence of obesity ${ }^{35}$. In our study we found higher ob/ow ratio value for female (1.12) than male subjects (0.59) in diabetics as well as in nondiabetics (1.00 and 0.62 in females and males respectively). This ratio was highest in diabetic females (Table II). In over-all population, irrespective of gender, the diabetic subjects had higher ob/ow ratio value $(0.84)$ than non-diabetics (0.79). The higher BMI can be seen in females in both diabetic and diabetic subjects (Table I). The results of our study suggest that obesity may be considered as a major etiological factor in the development of type 2 diabetes mellitus in this community.

Environmental as well as genetic factors contribute to the development of obesity ${ }^{33}$. Longini et $\mathrm{al}^{36}$ have estimated that the heritability for $\mathrm{BMI}$ is over $30 \%$ and the rest is accounted for by other factors, these include demographic factors, familial factors and personal factors. Obesity and leanness though run in families, yet do not follow a Mendelian pattern of inheritance. BMI, even within the non-obese level, is a dose-dependent risk factor for diabetes mellitus in middle-aged Japanese. Increase in BMl of $1 \mathrm{~kg} / \mathrm{m}^{2}$ (=body-weight gain of 2.4-2.9 $\mathrm{kg}$ ) may raise the risk by about $25 \%{ }^{37}$.

The higher prevalence and association of obesity and hypertension; correlated with DM shows a significant epidemiological transformation in this community. The coherent sedentary way of life has eventually resulted in precipitation of several multi-factorial traits both in males and females. Females are particularly more prone to sedentary life, and have thus showing higher ob/ow ratio. This study on diabetic and non-diabetic Makkans has revealed that the prevalence of HT is significantly higher in both male and female diabetics in comparison to nondiabetics. In males; the prevalence of HT is increased almost 5.81 times in the diabetic group, while in the female diabetics; the prevalence of HT is increased almost 19.68 times. Several studies showed close association between $\mathrm{HT}$ and $\mathrm{DM}^{14-16}$; even the prevalence of HT was reported to be almost $50 \%$ in the NIDDM patients ${ }^{38}$. Relationship between weight reduction and reduction in blood pressure ${ }^{39}$ reveals that reduction in weight is a promising step to control blood pressure or risk of hypertension.

Hypertension is a common problem among diabetic patients accelerating progression of vascular diabetic complications. It is significantly associated with old age, obesity, prolonged diabetic duration and poor glycemic control $^{40}$. The age-adjusted relative risk (RR) for new hypertension was highly associated with overweight status; men: RR, 1.46; women: RR, 1.7529; while Aucott et $\mathrm{al}^{41}$ found $10 \mathrm{~kg}$ weight loss with decrease of $4.6 \mathrm{~mm}$ $\mathrm{Hg}$ and $6.0 \mathrm{~mm} \mathrm{Hg}$ in diastolic and systolic blood pressure respectively, in a study of long-term effects of weight loss on hypertension showing the complexity of weight/hypertension relationship.

We also found statistically significant higher frequency of dyslipidemia in combined overweight-obese diabetic group of females than males; while in poor glycemic control $\left(\mathrm{HbA}_{1 \mathrm{c}}>10 \%\right)$ subjects, it was higher in females 
than male but statistically not significant (results not shown here). There were $69 \%$ of the total diabetic patients who had elevated $\mathrm{HbA}_{1 \mathrm{c}}$; showing poor glycemic control.There appeared to be no significant difference between males and females in the values of $\mathrm{HbA}_{1 \mathrm{c}}$ (Table I). The serum concentrations of triglycerides, cholesterol and LDL-C were significantly higher in diabetic patients as compared to control, and their correlation with $\mathrm{HbA}_{1 \mathrm{c}}$ were also statistically significant $(r=0.23 ; P<0.02, r=0.16 ; P<0.05, r=0.14 ; P<0.05$, respectively); but we could not find statistical difference of HDL-C level between diabetics and non-diabetics, rather no significant reduction in HDL-C which is a predictor of stroke in patients with $\mathrm{NIDDM}^{42}$, in our population.

Diabetes mellitus which apart from a disorder of glucose homeostasis also accompanies various degenerative manifestations such as accelerated aging, the events related to elevated levels of lipid peroxidation products in plasma of patients with diabetes mellitus ${ }^{43}$. Our results support the production of lipid peroxides in diabetes mellitus and that related significantly with glycosylated hemoglobin as we found that the plasma levels of $\operatorname{TBARS}(2.69 \mu \mathrm{M} \pm 0.15 \mathrm{SEM})$ is significantly higher in the diabetic patients as compared to those in control (1.97 $\mu \mathrm{M} \pm 0.12$ SEM).

Ethnic variation, overall physique, and genetic disorders all contribute to these disorders. Since the type 2 diabetic affects elderly of >35 year, a pathogenic mechanism initiated by insulin excess and resistance is suggestive. The strong association of obesity, type 2 diabetes and hypertension, has led to a new term "diabesity" for the association. The main link between obesity and type 2 diabetes is insulin resistance leading to excessive secretion of insulin to compensate, and maintain normoglycemia. Thus the resulting hyperinsulinemia, through some pathogenic mechanism, causes hypertension.
It is of significance that BP is controlled in diabetic patients. In Saudi Arabia, the prevalence of DM is high ${ }^{44}$, and with the increase in the prevalence of $\mathrm{HT}$ in diabetics, as shown in this study, the associated morbidity and complications are expected to increase. Hence, control of DM and HT by appropriate methods, particularly dietary restriction of calories and sodium, and regular physical exercise to decrease both the prevalence of HT and NIDDM are recommended. By losing weight, insulin receptors will increase in number, and also the post receptor abnormalities will improve by increasing both tissues sensitivity to insulin and glucose tolerance.

\section{REFERENCES}

1. Bray GA. Complications of obesity. Ann Intern Med 1985; 103: 1052-1062.

2. Bray GA. The syndromes of obesity, an endocrine approach. In: LJ DeGroot ed. Endocrinology, 3rd edition. Philadelphia: Saunders; 1995: Vol: 3, 2624.

3. Olefsky JM, Kolterman OG. Mechanisms of insulin resistance in obesity and non-insulin dependent (type II) diabetes. Am J Med 1981; 70: 151-168.

4. Kissebah AH, Freedman DS, Peiris AN. Health risks of obesity. Med Clin N Am 1989; 73: 111-138.

5. $\quad \mathrm{Pi}$-Sunyer FX. Health implications of obesity. Am J Clin Nutr 1991; 53: s1595- s1603.

6. Pi-Sunyer FX. Medical hazards of obesity. Ann Intern Med 1993; 199: 655-660.

7. Al-Riyami AA, Afifi MM. Prevalence and correlates of obesity and central obesity among Omani adults. Saudi Med J 2003; 24 (6): 641-646.

8. Ludwig DS, Ebbeling CB. Type 2 Diabetes Mellitus in Children; Primary Care and Public Health Consideration. JAMA 2001; 286 (12): 1427-1430.

9. Flegal KM, Carroll MD, Kuczmarski RJ, Johnson CL. Overweight and obesity in the United States, 
prevalence and trends (1960-1994). Int $J$ Obes Relat Metab Disord 1998; 22: 39-47.

10. Effects of weight loss and sodium reduction intervention on blood pressure and hypertension incidence in overweight people with high-normal blood pressure. The Trials of Hypertension Prevention, phase II. The Trials of Hypertension Prevention Collaborative Research Group. Arch Intern Med 1997; 157 (6): 657-667.

11. King RA, Rotter JI, Motulsky AG, eds. The genetic basis of commondiseases Oxford, Oxford University Press; 1992: 413-481.

12. Mueller RF, Young ID. Emery's Elements of Medical Genetics, 9th edition. London, Churchill Livingstone; 1995.

13. Genest J, Kuchel O, Hamet P, Cantin M, eds. Hypertension, physiopathology and treatment, 2nd edition. New York, McGraw Hill Book Company; 1983: 408-427.

14. Sowers JR, Khoury S. Diabetes and hypertension, a review. Prim Care 1991; 18: 509-524.

15. Tai TY, Chuang LM, Chen CJ, Lin BJ. Link between hypertension and diabetes mellitus, epidemiological study of Chinese adults in Taiwan. Diabetes Care 1991; 14: $1013-1020$.

16. Epstein M. Diabetes and hypertension, the bad companions. J Hypertens 1997; 15 (Suppl): s55-s62.

17. DeFronzo RA, Ferrannini E. Insulin resistance, a multifaceted syndrome responsible for NIDDM, obesity, hypertension, dyslipidemia and atherosclerotic cardiovascular disease. Diabetes Care 1991; 14: 173-194.

18. DeFronzo RA. Insulin resistance, a multifaceted syndrome responsible for NIDDM, obesity, hypertension, dyslipidaemia and atherosclerosis. Neth J Med 1997; 50: 191-197.

19. West KM: Epidemiology of diabetes and its vascular lesions, New York, Elseveir (1978).

20. McGill MJ, Donnelly R, Molyneaux L, Yue DK. Ethnic differences in the prevalence of hypertension and proteinuria in NIDDM. Diabetes Res Clin Pract 1996; 33: 173-179.

21. Raleigh VS. Diabetes and hypertension in Britain's ethnic minorities, implications for the future of renal services. BMJ 1997; 314: 209-213.

22. Assiri AM, Sultan AMN, Khan ZA. The pattern of dyslipidemia and lipid peroxides level in type 2 diabetes mellitus patients in Makkah. Pak J Biochem and Mol Bio 2002; 35: 92-100.

23. World Health Organization Study Group on Diabetes Mellitus, WHO Technical eport Series, Geneva No. 727, 1985.

24. Williams G, Pickup JC. In: Handbook of Diabetes, 2nd edition. Chapter 3; Blackwell Science Inc. MA, USA; 1999 16.

25. Bunn HF. Evaluation of glycosylated hemoglobin in diabetic patients. Diabetes 1981; 30: 613-617.

26. Esterbauer H, Cheeseman KH. Methods Enzymol 1990; 186: 407-421.

27. World Health Organization, Measuring Obesity, Classification and Description of Anthropometric Data Report on a WHO Consultation on the Epidemiology of Obesity. Copenhagen: WHO Regional Office for Europe, Nutrition Unit, 1988.

28. Garrow JS, Webster J. Quetelets Index (W/HZ) as a measure of fatness. Int J Obese 1985; 9: 147-153.

29. Wilson PW, D'Agostino RB, Sullivan L, Parise H, Kannel WB. Overweight and obesity as Determinants of Cardiovascular Risk, The Framingham Experience. Arch Intern Med 2002; 162: 1867-1872.

30. World Health Organization, Report of WHO Expert Committee on Hypertension, WHO Tech. Rep. Series. Geneva: World Health Organziation, 1979. 
31. Jafar TH, Levey AS, Jafary FH, White F, Gul A, Rahbar $\mathrm{MH}$, et al. Ethnic subgroup differences in hypertension in Pakistan. J Hypertens 2003; 21 (5): 905-912.

32. World Health Organization, Prevention and Control of Diabetes Mellitus, in Handbook of Resolutions, Vol. III 2nd Ed. (1985-1989). Geneva: World Health Org , 1990 , 71 WHA: 42.

33. Bouchard C. Genetic aspects of human obesity. In Bjorntorp P, Brodoff BN, eds. Obesity. Lippinott Company, Pennsylvania; 1992: 343-351.

34. King H, Taylor R, Zimmet P, Pargeter K, Raper LR, Beriki $T$, et al. Non-insulin-dependent diabetes (NIDDM) in a newly independent Pacific nation: the Republic of Kiribati. Diabetes Care 1984; 7(5): 409-415.

35. Al-Nuaim AR. Population-Based Epidemiological Study of the Prevalence of overweight and obesity in Saudi Arabia, Regional Variation. Ann Saudi Med 1997; 17 (2): 195-199.

36. Longini IM Jr, Higgins MW, Hinton PC, Moll PP, Keller JB. Genetic and environmental sources of familial aggregation of body mass in Tecumseh, Michigan. Hum Biol 1984; 56 (4): 733-757.

37. Nagaya T, Yoshida H, Takahashi H, Kawai M. Increases in body mass index, even within non-obese levels, raise the risk for Type 2 diabetes mellitus, a follow- up study in a Japanese population. Diabet Med 2005; 22 (8): 1107-1111.
38. Daly PA, Landsberg L. Hypertension in obesity and NIDDM, role of insulin and sympathetic nervous system. Diabetes Care 1991; 14: 240-248.

39. Stevens VJ, Obarzanek E, Cook NR, Lee IM, Appel LJ, Smith West $D$, et al. Long-term weight loss and changes in blood pressure: results of the Trials of Hypertension Prevention, phase II. Ann Intern Med 2001; 134 (1): 1-11.

40. Kheir MM, Ahmed AM, Elbalaa A. Hypertesion in type 2 diabetic patients. Saudi Med J 2003; 24 (6): 690-691.

41. Aucott L, Poobalan A, Smith WC, Avenell A, Jung R, Broom J. Effects of weight loss in overweight/obese individuals and long-term hypertension outcomes, a systematic review. Hypertension 2005; 45: 1035-1041.

42. Lehto S, Ronnemaa T, Pyorala K, Laakso M. Predictors of stroke in middle- aged patients with non-insulin dependent diabetes. Stroke 1996; 27: 63-68.

43. Jain SK, McVie R, Duett J, Herbst JJ. Erythrocyte membrane lipid peroxidation and glycosylated haemoglobin in diabetes. Diabetes 1989; 38: 15391543.

44. El-Hazmi MAF, Warsy AS, Al-Swailem AR, AI-Swailem Sulaimani $R$. Diabetes mellitus a health problem in Saudi Arabia and its complications. Eastern Mediterr Health J 1998; 4: 58-67. 